
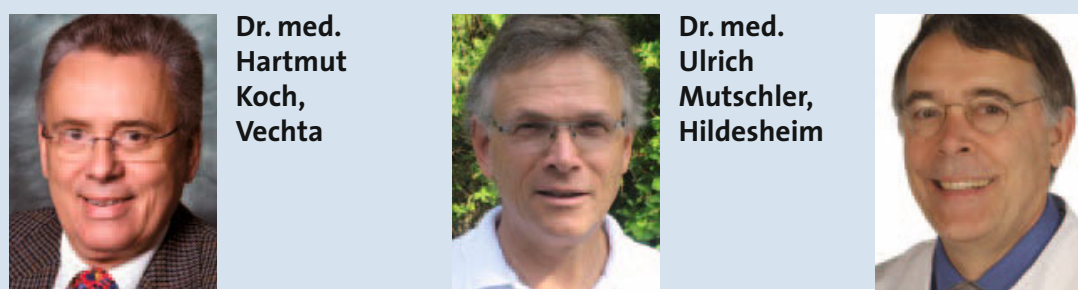

Prof.

Dr. med. Jörg Ritter, Münster

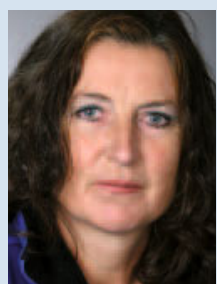

Dr. med.

Kirsten

Stollhoff,

Hamburg

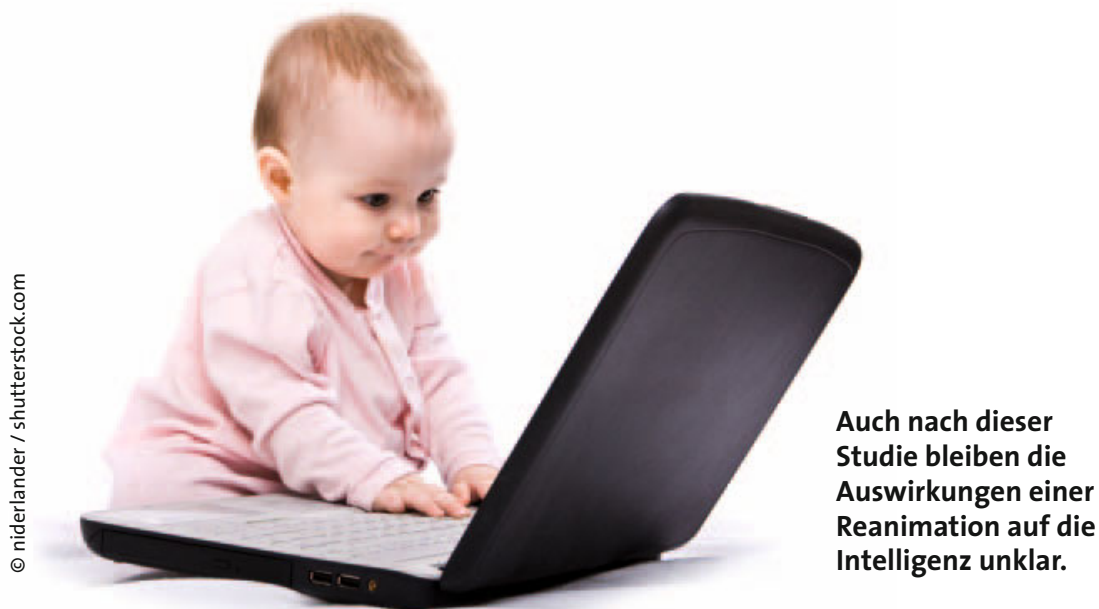

nachfolgende Enzephalopathie deutlich größer als die mit nachfolgender Enzephalopathie. Deshalb war die Häufigkeit einer Intelligenzminderung bezogen auf die gesamte Population bei Kindern ohne Enzephalopathie nach Reanimation fast dreimal so hoch $(3,4 \%)$ als bei
Kindern, die eine Enzephalopathie entwickelten $(1,2 \%)$.

Kommentar: Die Autoren halten es noch nicht für sicher erwiesen, dass zwischen der Intelligenzminderung und der Reanimationsbedürftigkeit nach der Ge- burt bei sonst unkomplizierten Verlauf ohne Enzephalopathie ein Zusammenhang besteht. Wenn es wirklich einen kausalen Zusammenhang gäbe, würde dies bedeuten, dass einer von 30 Erwachsenen mit Intelligenzminderung seine Hirnschädigung unter oder während der Geburt erworben hat, obwohl es noch nicht zu einer klinisch manifesten Enzephalopathie kam. Eines zeigt diese Studie wiederum deutlich: Nachbeobachtungszeiten müssen lange genug gewählt werden, um verwertbare Ergebnisse zu erzielen.

Dr. Hartmut Koch

Odd DE et al. Resuscitation at birth and cognition at 8 years of age: a cohort study. Lancet 2009; 373: 1615-22

\section{Schienung peripherer Zugänge bei Frühgeborenen unnötig}

\section{Eine indische Untersuchung konnte zeigen, dass das Anlegen von Schienen bei Frühgeborenen nicht zu einer längeren Liegedauer von Venenzugängen führt.}

Die ie Schienung einer Extremität, an der ein peripherer Venenzugang angelegt wurde, ist ein weit verbreitetes Vorgehen. Man erhofft sich durch die relative Immobilisation der angrenzenden Gelenke eine niedrigere Rate an Dislokationen.

Im Rahmen einer randomisierten Studie wurden bei 33 peripheren Venenzugängen die Extremitäten nach einem einheitlichen Vorgehen geschient, als Kontrollgruppe dienten 36 Frühgeborene, bei denen nicht geschient wurde. Die Frühgeborenen hatten ein Gestationsalter von 30-35 SSW und wogen 930-1.510 g. Zielgröße war die Liegedauer des Venenzuganges. Dabei war vorgegeben, dass die Kanüle im Falle eines Paravasats, einer Okklusion oder einer Entzündung entfernt werden musste.

Die Liegedauer war in der Gruppe der geschienten Venenzugänge mit 23,5 h etwas kürzer als in der nicht geschienten Gruppe mit 26,9 h. Dieser Unterschied war statistisch nicht signifikant. Die häufigste Ursache für die Entfernung war ein Paravasat (jeweils um 80\%).
Kommentar: Obwohl die Maßnahme rein logisch betrachtet Sinn ergibt - in dieser Studie führte das Schienen zum Schutz eines peripheren Venenzuganges nicht zu einer längeren Liegedauer. Es ist vorstellbar, dass Paravasate durch den Druck der Pflaster, die die Schiene fixieren, sogar begünstigt werden und so den Erfolg der Methode mindern. Offen bleibt, ob die Methode bei reiferen Neugeborenen mit mehr Aktivität und höherem Muskeltonus mehr Nutzen hat und ob eventuell eine andere Art der Fixierung erfolgreicher ist.

Dr. Levente Bejo

Dalal SS et al. Limb splinting for intravenous cannulae in neonates: a randomised controlled trial. Arch Dis Child Fetal Neonatal Ed 2009; 94; F394-6 